ESTRATÉGIA 


\title{
PRÁTICAS ESTRATÉGICAS DE NEGOCIAÇÃO EM REDES DE COOPERAÇÃO
}

\author{
STRATEGIC PRACTICES OF NEGOTIATION IN COOPERATION NETWORK
}

Cristiano Klanovicz

Centro Universitário Ritter dos Reis

Jorge Renato de Souza Verschoore Universidade do Vale do Rio dos Sinos

Carlo Franzato

Universidade do Vale do Rio dos Sinos

\author{
Data de submissão: 08 dez. 20 | 6. Data de aprovação: \\ 04 jul. 20 ।7. Sistema de avaliação: Double blind review. \\ Universidade FUMEC / FACE. Prof. Dr. Henrique Cordeiro \\ Martins. Prof. Dr. Cid Gonçalves Filho.
}

\section{RESUMO}

O objetivo desta pesquisa é identificar as práticas estratégicas de negociação com fornecedores adotadas pelas redes de cooperação e analisá-las através da perspectiva teórica da Estratégia como Prática Social. O método empregado pela pesquisa foi desdobrado em duas etapas com procedimentos distintos. Inicialmente, foi aplicada uma survey em 50 redes de cooperação, permitindo a seleção de 14 redes com características similares, que foram analisadas mais detalhadamente por meio de entrevistas em profundidade e coleta documental a fim de manter coerência com a abordagem da Estratégia como Prática Social. Três práticas estratégicas foram identificadas: equipe de negociação, manual de negociação e tecnologia extranet.A partir das evidências obtidas, foi possível perceber que as três práticas identificadas se revelam como estratégicas, pois aumentam o potencial de ganho das empresas associadas, além de fortalecerem a organização e colaboração em rede, uma vez que incentivam a manutenção de mecanismos sociais entre seus integrantes.

\section{PALAVRAS-CHAVE}

Redes de Cooperação. Estratégia como Prática Social. Negociação. Práxis. Praticantes. 


\section{ABSTRACT}

The objective of this research is to identify the strategic business practices with suppliers adopted by cooperation networks and analyze them through theoretical perspective Strategy as Social Practice. The method used in the survey was split into two stages with different procedures. Initially it was applied survey in 50 networks of cooperation, allowing the selection of 14 networks with similar characteristics that have been analyzed in detail through interviews and document collection in order to maintain consistency with the approach of Strategy as Social Practice. Three strategic practices were identified: negotiating team; manual trading and extranet technology. It was revealed that the three practices identified are revealed as strategic as they increase the potential of gain of associated firms, as well as strengthen the organization and network cooperation, since it fosters the maintenance of social mechanisms among members.

\section{KEYWORDS}

Cooperation Networks. Strategy as Social Practice. Negotiation. Praxis. Practitioners.

\section{INTRODUÇÃO}

O fenômeno das redes de cooperação tem recebido crescente atenção nos estudos das práticas organizacionais (OLIVER; EBERS, 1998). Esse interesse decorre do conjunto de transformações socioeconômicas ocorridas nas última décadas, tais como a expansão dos mercados globais, rapidez dos avanços tecnológicos e maior fluxo de informações, que formaram um contexto no qual as iniciativas de redes são vistas como alternativas estratégicas capazes de tornar as pequenas e médias empresas mais competitivas no mercado (NOHRIA, 1992). Para tanto, as empresas buscam reunir atributos e competências centradas na compreensão de que as dificuldades e oportunidades comuns podem ser superadas e alcançadas mediante a realização de ações conjuntas (VERSCHOORE; BALESTRIN, 20I0).
Entre as diversas ações desenvolvidas pelas redes de cooperação, a negociação com fornecedores ganha relevância por ampliar o poder de barganha nas relações econômicas e possibilitar a realização de acordos comerciais em condições exclusivas que atendam os interesses dos atores envolvidos (WAARDEN, 1992; CAMPBELL; GOOLD, 1999). Ao constituir um arranjo robusto por meio do alinhamento estratégico entre as empresas associadas, a rede torna-se capaz de estabelecer novas relações comerciais e alcançar novas oportunidades que não seriam possíveis caso as organizações integrantes atuassem isoladamente no mercado (HUMAN; PROVAN, 1997).

Apesar da compreensão de que as redes preconizam maior poder de negociação e ganhos em escala para seus integrantes (CAMPBELL; GOOLD, 1999; 
VERSCHOORE; BALESTRIN, 2008), por se tratar de um fenômeno relativamente recente, ainda não existem modelos consolidados de gestão voltados à identificação das práticas estratégicas adotadas pelas redes. No contexto da negociação, a diversidade de atores e de seus interesses torna essa identificação ainda mais complexa, exigindo que diversos parâmetros sejam considerados em relação aos potenciais fornecedores, como o trabalho coletivo, vantagens em relacionamentos de longo prazo, descontos em grandes volumes, garantias de entrega, entre outros (BORTOLASO; PERUCIA, 20I0).

$O$ presente artigo se insere neste contexto, abordando como campo empírico 14 redes de empresas varejistas formadas pelo Programa Redes de Cooperação do Governo do Estado do Rio Grande do Sul. O principal objetivo é identificar as práticas estratégicas de negociação com fornecedores adotadas pelas redes de cooperação e analisá-las através da perspectiva teórica Estratégia como Prática Social (EPS). Derivada dos estudos da teoria social sobre a prática, a EPS considera o processo estratégico como um enredo das múltiplas ações dos atores que colaboram no âmbito de uma organização, as interações que se articulam entre eles e com a sociedade (WHITTINGTON, 1996). Assim, a EPS propõe estudar o processo estratégico a partir dessas ações e interações, considerando a estratégia como o conjunto de práticas sociais difusas e abrangentes em uma organização, desenvolvida de forma contínua pelos seus praticantes (JOHNSON, 2007).

Nesta direção, este artigo procura aprofundar as dicussões sobre as estratégias em redes de cooperação, em particular, contribuindo para a identificação das práticas de negociação com fornecedores adotadas nestas iniciativas. Com o propósito de alcançar o objetivo proposto, o artigo está organizado em 5 seções além desta introdução. Inicialmente, é realizada uma reflexão sobre os principais aspectos conceituais das redes de cooperação e o papel da negociação com fornecedores nessas iniciativas. Na sequência, é apresentada uma revisão sobre os conceitos que constituem a abordagem da EPS, seguida pelo método com ênfase nos procedimentos de coleta e de análise qualitativa dos dados. $O$ capítulo seguinte visa a apresentação das práticas estratégicas identificadas. Por fim, o capítulo de discussão e conclusões destaca as principais implicações em âmbito teórico e prático, as limitações, bem como os apontamentos para estudos futuros.

\section{ESTRATÉGIA COLETIVA NAS REDES DE COOPERAÇÃO}

As redes de cooperação consistem em arranjos compostos por um grupo de empresas formalmente relacionadas, com prazo ilimitado de existência e escopo múltiplo de atuação, na qual cada empresa mantém sua individualidade legal, participa diretamente das decisões e divide de modo igualitário os ganhos alcançados pelo esforço coletivo (BALESTRIN; VERSCHOORE, 2008). A ideia central do estabelecimento de uma rede de cooperação é reunir atributos que permitam a adequação das empresas ao ambiente competitivo através de uma estrutura única, porém descentralizada, tendo em vista sustentar objetivos comuns e superar obstáculos, tais como as mudanças acentuadas na tecnologia e a concorrência elevada do mercado (MILES; SNOW, 1986; AMATO NETO, 2005; BALESTRIN;VERSCHOORE, 2008). 
Enquanto um espaço socialmente constituído, as redes de cooperação pressupõem uma relação de colaboração e interdependência. Se, por um lado, as empresas percebem que, isoladamente, não são capazes de desenvolver os recursos necessários à competição, por outro, através da união e colaboração, tais recursos podem ser mais facilmente acessados para o aumento da competitividade no mercado (PERROW, 1993; GRANDORI; SODA, 1995). Desse modo, enquanto o termo rede é empregado para justificar o relacionamento vantajoso entre três ou mais empreendimentos individuais, o termo cooperação é utilizado por ser o conceito fundamental que norteia as ações dos participantes (VERSCHOORE, 2006).

Para Balestrin e Verschoore (2008, p.|5I), "a formação de redes pressupõe a relação de três condições fundamentais: objetivos comuns, interação e gestão”. A interação social entre os atores da rede proporciona a identificação de objetivos comuns que são transformados em ganhos competitivos através da execução de ações estratégicas que compõem a gestão. Esse processo retroalimenta o ambiente de cooperação entre os atores envolvidos, pois os ganhos alcançados estimulam a criação de relacionamentos mais consistentes e a definição de novos objetivos que possam ser alcançados coletivamente pelos seus integrantes (BALESTRIN; VERSCHOORE, 2008; BORTOLASO, 2009).

Constituída por uma diversidade de atores que passam a interagir e integrar o sistema organizacional, as redes de empresas configuram um cenário bastante complexo e a sua formação não garante os ganhos que se pode obter através da cooperação (VERSCHOORE; BALESTRIN, 2008;WEG-
NER; PADULA, 2012 ). Para tanto, as organizações em rede promovem estratégias coletivas, ou seja, a formulação conjunta de políticas e a implementação de ações (ASTLEY, 1984). Dessa forma, elas conseguem diminuir as incertezas do mercado e sustentar vantagens competitivas a partir de uma estrutura colaborativa, de relações sinérgicas e do aprendizado mútuo (EBERS; JARILLO, 1998).

Um desses processos refere-se à negociação com fornecedores (CAMPBELL; GOOLD, 1999). Hames (20I2) considera a negociação uma atividade social em que as pessoas interagem entre si visando a formação acordos e a resolução de conflitos. Embora as definições de negociação apresentem diferenças em alguns aspectos, os autores que abordam a temática compratilham elementos em comum: (I) existem dois ou mais participantes interdependentes, (2) cada um deles tem objetivos individuais que podem ser parcialmente incompatíveis. A negociação consiste em um (3) processo em que (4) alternativas são investigadas (5) com o propósito de se chegar a um acordo entre ambas as partes (DE MOOR;WEIGAND, 2004).

Nas redes de cooperação, a negociação é uma atividade que procura atender alternativas de ganho comum entre os associados através das transações econômicas com fornecedores (FISHER; URY; PATTON, 2005). Entre as possibilidades de estruturar o processo de negociação, algumas redes optam por constituir uma equipe como intermediadora responsável por gerenciar e acompanhar o processo de compra. Assim, a peculiaridade da estratégia nas redes está nos atores que, agrupados em equipes estratégicas formadas pelos próprios associados, devem se acordar sobre a alocação 
de tarefas e procedimentos operacionais a fim de realizar suas atividades (GRANDORI; SODA, 1995).

Segundo Bortolaso e Perucia (2010), a compra pode ser realizada via central da rede, na qual os pedidos são centralizados, reunidos pela sede da rede e repassados para os associados. Em outras situações, as redes também podem utilizar tecnologias e softwares pelos quais os associados podem ter acesso aos produtos e preços, assim como realizar os seus próprios pedidos individualmente. Em ambos os casos, os associados recebem vantagens dos fornecedores em função de integrar a rede (BORTOLASO; PERUCIA, 20I0).

Outra questão importante no que se refere à negociação diz respeito à simetria com que a atividade é realizada. A maioria das redes de cooperação tem como princípio negociar com fornecedores que proporcionem condições iguais de pagamento para todas as empresas associadas como um meio de atrair novos membros e fortalecer os já pertencentes às redes (BORTOLASO; PERUCIA, 20 I0). Assim, o êxito da negociação é alcançado na medida em que um maior número de participantes passam a integrar a rede, pois somente com o crescimento do número de associados e do volume de compras, é possível atingir condições favoráveis à negociação, como ganhos em escala e poder de mercado (VON ENDE, 2004; BALESTRIN;VERSCHOORE, 2008).

A escala e o poder de mercado comportam a geração de melhores oportunidades em termos de preços, prazos, condições de pagamento e prioridade de entrega (WAARDEN, 1992). Ao tornar uma organização robusta, a rede amplia a capacidade de atrair fornecedores de expres- são e qualidade, além de gerar marcas com reconhecimento, alcançando maior exposição pública (LORENZONI; BADENFULLER, 1995). Tais benefícios não estão apenas relacionados ao enfrentamento da concorrência, mas também ao acréscimo de representatividade e credibilidade junto ao mercado. A credibilidade gera maior reconhecimento por parte dos demais atores envolvidos com a rede, garantindo maior legitimidade nas ações empresariais (DIMAGGIO; POWELL, I 983).

Ao possibilitar a obtenção de resultados financeiros favoráveis para as empressas associadas, a negociação com fornecedores se destaca como um dos principais atrativos para a formação e desenvolvimento das redes de cooperação (BALESTRIN; VERSCHOORE, 2008; BORTOLASO; PERUCIA, 2010). Considerando as redes como espaços de construção e desenvolvimento coletivo, as estratégias de negociação podem ser estudadas como práticas sociais em que os atores trabalham conjuntamente no sentido de maximizar o potencial de ganho destas atividades estratégicas. Assim, com o intuito de dar enfoque às práticas cotidianas que produzem a estratégia de negociação, o próximo capítulo apresenta a compreensão da "Estratégia como Prática Social" como abordagem teórica adotada pelo presente estudo.

\section{ESTRATÉGIA COMO PRÁTICA SOCIAL}

Durante décadas, o campo de estudo da estratégia organizacional foi dominado pela utilização de modelos de análise que reduziam a atuação dos atores de uma organização a variáveis estatísticas relacionadas ao desempenho das empresas (JARZABKOWSKI, 2005). De acordo com tais modelos, o es- 
trategista poderia elaborar as estratégias de uma organização sem necessariamente mergulhar em seus processos (WILSON; JARZABKOWSKI, 2004). Os planos previamente definidos pela alta gestão seriam logo executados pelos demais atores de uma organização e sua execução seria controlada por meio do alcance das metas estabelecidas.

Nos últimos vinte anos, tornou-se cada vez mais clara a importância da operacionalização desses planos para a elaboração estratégica. Diversos autores passaram a considerar a estratégia como um processo social de ação e interação entre todos os atores que colaboram no âmbito de uma organização (WHITTINGTON, 1996).

$\mathrm{Na}$ abordagem da EPS, a estratégia é entendida como o conjunto de práticas organizacionais cotidianas socialmente constituídas (JARZABKOWSKI; SPEE, 2009). Considerando que nenhum ator é capaz de realizar individualmente uma atividade complexa sem a contribuição de outros participantes, os atores devem interagir entre si, dialogando, colaborando e, assim, moldando o contexto no qual estão inseridos. $O$ surgimento de novas práticas nas organizações provoca tensões com as práticas antigas, permitindo sua evolução (JARZABKOWSKI, 2005).

$\mathrm{Na}$ perspectiva da EPS, dicotomias como pensar/agir e formular/implementar são supridas no constante movimento coletivo de construção das práticas estratégicas (JARZABKOWSKI, 2005). As práticas estratégicas compreendem "a habilidade astuciosa para usar, adaptar e manipular os recursos empregados para engajar-se na formação da atividade da estratégia ao longo do tempo" (JARZABKOWSKI, 2005, p.34). As práticas são consideradas estratégicas quando apresentam um curso de ação contínuo, engendrado para lidar com alguma determinada situação, gerando maior desempenho e competitividade para as organizações (MINTZBERG; AHLSTRAND; LAMPEL, 2000; JOHNSON; MELIN; WHITTINGTON, 2003;WHITTINGTON, 2004).

A EPS como abordagem de investigação das práticas estratégicas atua sobre as condutas, interações, métodos, técnicas e ferramentas adotadas pelos atores sociais, considerando a consciência que eles detêm sobre os procedimentos de uma ação, ou seja, o conhecimento que é compartilhado por todos os atores sociais presentes no ambiente organizacional (JOHNSON; MELIN; WHITTINGTON, 2003). O estudo da prática estratégica procura, portanto, conciliar a atuação e ações dos agentes humanos sem, por outro lado, desconsiderar os fatores externos às organizações que são referências para aqueles mesmos agentes em um processo de interação social (GOFFMAN, I 983).

Outra implicação do ponto de vista metodológico no emprego da EPS consiste na interpretação de três componentes relacionados com o fazer estratégico: prática, práxis e praticantes. A prática consiste no conjunto rotineiro e articulado de atividades que colaboram no âmbito estratégico de uma organização (WHITTINGTON, 2006). Para Jarzabkowski (2004), a prática implica um desempenho repetitivo de um conjunto de atividades com o objetivo de tornar-se recorrente e habitual para ratificar determinada estratégia. No emprego da EPS, a investigação das práticas tende a identificar questões como: quais as práticas utilizadas? Como as práticas são empregadas? Quais as alterações que estas sofrem com sua utilização? Quais fatores da organização contribuem para o desenvolvimento da estratégia? (JARZABKOWSKI; 
BALOGUN; SEIDL, 2007). A utilização de objetos, softwares de gestão e tecnologias podem ser consideradas práticas estratégicas desde que sejam rotinas compartilhadas entre os atores e resultem em um impacto positivo para o desempenho da organização (MANTERE, 2005; JARZABKOWSKI; BALOGUN; SEIDL, 2007).

A práxis, por sua vez, compreende as atividades realizadas pelos praticantes no que se refere ao trabalho intraorganizacional exigido para realizar determinada prática estratégica (WHITTINGTON, 2002). De acordo com Whittington (2006), a práxis recorre a uma atividade atual, tal como reuniões, workshops e intervenções de consultorias pelas quais os atores interagem para a execução da prática estratégica. Assim, a práxis busca descrever o trabalho dos praticantes da estratégia, conforme eles desempenham, modificam e replicam atividades e comportamentos no dia a dia das organizações (WHITTINGTON, 2002).

Já os praticantes são considerados os atores sociais que desenvolvem a práxis e as práticas, combinando, coordenando e adaptando as práticas conforme suas necessidades de utilização e, como consequência, institucionalizando as novas práticas resultantes (JARZABKOWSKI; BALOGUN;
SEIDL, 2007). Do ponto de vista da EPS, os praticantes são os atores sociais que participam ativamente do processo de construção e reconstrução da estratégia, produzindo impacto sobre ela. As características pessoais dos praticantes acabam por moldar a estratégia através das suas percepções de mundo, comportamentos, cultura e atitudes (JARZABKOWSKI, 2003;WHITTINGTON, 2006). Jarzabkowski e Spee (2009) ressaltam que uma das características da EPS é a aproximação do pesquisador com os praticantes como uma forma de coletar informações sobre os indivíduos, suas ações e o contexto no qual eles estão inseridos a partir de um ponto de vista crítico.

Sendo assim, a EPS procura compreender como atores estratégicos (praticantes) constituem e reconstituem o sistema de práticas estratégicas compartilhadas (práticas) que envolvem os instrumentos $e$ ferramentas disponíveis nas organizações para auxiliar tal processo nas atividades do cotidiano (práxis) para se fazer a estratégia (SCHATZKI, 1996; WILSON; JARZABKOWSKI, 2004). A estratégia passa, portanto, a ser interpretada por meio da interação destes três conceitos como objetos de análise. Cada um deles é descrito resumidamente no Quadro I.

\section{QUADRO 1 - Componentess da Estratégia como Prática Social}

\begin{tabular}{|l|l|l|}
\hline Componentes & Descrição & Autores \\
\hline Prática & $\begin{array}{l}\text { Compreende o conjunto articulado e repetitivo de atividades que } \\
\text { colaboram no âmbito estratégico de uma organização. }\end{array}$ & \multirow{2}{*}{ Jarzabkowski (2003); Whittington } \\
Práxis & $\begin{array}{l}\text { Consiste nas atividades realizadas pelos praticantes no que } \\
\text { se refere ao trabalho intraorganizacional exigido para realizar, } \\
\text { desenvolver ou modificar determinada prática estratégica. }\end{array}$ & $\begin{array}{l}\text { (2002); Whittington (2006); } \\
\text { Jarzabkowski, Balogun e Seidl }\end{array}$ \\
\hline Praticantes & $\begin{array}{l}\text { Refere-se aos atores da estratégia, isto é, os estrategistas que } \\
\text { desenvolvem as práticas e que realizam a práxis. }\end{array}$ & $\begin{array}{l}\text { (2009). } \\
\end{array}$
\end{tabular}

Fonte: produzido pelo autores. 
A abordagem EPS permite ampliar o horizonte de investigação do pesquisador uma vez que se torna possível visualizar e compreender as estratégias como resultantes de um conjunto de práticas vivenciadas e manifestadas no cotidiano dos agentes organizacionais. Johnson (2007) apresenta quatro benefícios principais das pesquisas sobre EPS: dirigir-se às pessoas que realmente administram, constroem e praticam as estratégias; oferecer um nível mais profundo de análises e de explicações para as especificidades estratégicas; prover mecanismos os quais contribuam para adicionar insights que interessem ao desenvolvimento estratégico organizacional; e oferecer uma agenda de pesquisa rica que possa levar os pesquisadores a muitas direções.Assim, buscando investigar as práticas de negociação com fornecedores adotadas pelas redes de cooperação a partir da abordagem da EPS, o próximo capítulo apresenta o método adotado, destacando os procedimentos de coleta e análise dos dados.

\section{MÉTODO}

A partir da base teórica apresentada, a presente pesquisa buscou investigar as práticas estratégicas de negociação de 14 redes de empresas varejistas formadas pelo Programa Redes de Cooperação (PRC) do Governo do Estado do Rio Grande do Sul. Concebido no ano 2000, o PRC é resultado de uma política pública que visa ao desenvolvimento regional através do fortalecimento da cooperação entre pequenas e médias empresas, estabelecendo-se a partir de três principais pilares: a) uma metodologia de formação e consolidação das redes de cooperação; b) uma estrutura regionalizada de suporte às redes formada pelas universidades regionais; e c) uma co- ordenação central por parte do Governo do Estado, responsável pelos instrumentos de promoção, orientação e apoio aos empresários e gestores das redes. Desde a formação do PRC até hoje, foram estabelecidas mais de 200 redes de cooperação, as quais abrangem cerca de 7 mil empresas e 80 mil postos de trabalho (SDECT, 20 I5).

De natureza exploratória, a pesquisa foi desdobrada em três etapas com procedimentos distintos. Inicialmente, foi aplicada uma survey em 50 redes do PRC, permitindo a seleção de 14 redes com características similares para o escopo da pesquisa. Logo, tais redes foram analisadas mais detaIhadamente através de entrevistas em profundidade e coleta documental, permitindo um olhar mais profundo sobre as práticas estratégicas de negociação adotadas.

A survey operada na primeira etapa foi de tipo transversal, aplicada em 50 redes do segmento varejista considerando diferentes setores de atuação e tempo de existência distintos. Tais redes foram analisadas por meio de um instrumento de avaliação da gestão de redes de cooperação desenvolvido por Bortolaso (2009), aplicado por dois técnicos especialistas em redes de cooperação. $O$ instrumento prevê 46 questões de análise bastante abertas, subdivididas em quatro critérios de avaliação: estratégia, estrutura, processos e resultados. Cada critério foi medido em uma escala específica de cinco pontos:

- Nível I - Iniciante: ainda faltam os requisitos mínimos;

- Nível 2 - Básico: estágio de construção e mapeamento;

- Nível 3 - Intermediário: estágio de aprendizagem;

- Nível 4 - Adequação: consolidação e melhoria; 
- Nível 5 - Referência: rede totalmente incrementada e sistematizada.

Os resultados foram analisados e classificados a partir das respostas e evidências coletadas em campo. As redes que obtiveram uma pontuação média superior ou igual a 4,00 (adequação e referência) nas questões relacionadas aos processos de negociação com fornecedores foram selecionadas para a etapa posterior de coleta e análise qualitativa para que, assim, fosse possível mapear as práticas de negociação mais consistentes. Um total de 14 redes foram selecionadas. A Tabela I apresenta 0 número de associados, o tempo de existência e a pontuação média para cada uma das 14 redes selecionadas. Com intuito de preservar a identidade das redes, das empresas associadas e dos respondentes, informações como os nomes das entidades e dados dos entrevistados foram omitidos.

$\mathrm{Na}$ segunda etapa, entrou-se no cerne do estudo, analisando as práticas de negociação das 14 redes selecionadas por meio de entrevistas em profundidade e coleta documental. A entrevista em profundidade é caracterizada por permitir flexibilidade para o pesquisador questionar o respondente no esclarecimento dos pontos essenciais para a compreensão da realidade investigada e avaliar a veracidade das respostas, mediante a observação do comportamento e da busca por evidências empíricas (TRIVINOS, 1990). Para as entrevistas, foi utilizado um questionário semiestruturado construído com base nas questões já relatadas pelos entrevistados na primeira etapa quanto ao processo e práticas de negociação, que foi sendo adaptado ao longo de sua aplicação na medida em que novas questões pertinen-

TABELA 1 - Características das 14 redes selecionadas para análise qualitativa

\begin{tabular}{l|c|c|c}
\hline Redes & Número de Associados & Tempo de existência & Pontuação média \\
\hline Rede 01 & 33 associados & 08 anos & 5,00 \\
\hline Rede 02 & 36 associados & 12 anos & 5,00 \\
\hline Rede 03 & 23 associados & 13 anos & 4,67 \\
\hline Rede 04 & 300 associados & 14 anos & 4,50 \\
\hline Rede 05 & 62 associados & 14 anos & 4,50 \\
\hline Rede 06 & 20 associados & 07 anos & 4,33 \\
\hline Rede 07 & 45 associados & 13 anos & 4,33 \\
\hline Rede 08 & 160 associados & 13 anos & 4,33 \\
\hline Rede 09 & 19 associados & 12 anos & 4,17 \\
\hline Rede 10 & 07 associados & 14 anos & 4,00 \\
\hline Rede 11 & 09 associados & 06 anos & 4,00 \\
\hline Rede 12 & 30 associados & 10 anos & 4,00 \\
\hline Rede 13 & 68 associados & 10 anos & 4,00 \\
\hline Rede 14 & 205 associados & 08 anos & 4,00 \\
\hline Fone: pros & & \\
\hline
\end{tabular}

Fonte: produzido pelo autores 
tes ao objetivo do estudo foram surgindo. $O$ questionário foi aplicado por dois técnicos especialistas em redes de cooperação previamente treinados para coletar os dados seguindo três procedimentos: I) visitar as redes de cooperação; 2) entrevistar os respondentes alvos; e 3) buscar evidências para sustentar a identificação das práticas estratégicas. Três representantes de cada uma das 14 redes selecionadas foram entrevistados - o presidente e dois associados - totalizando 42 entrevistas com duração média de 60 minutos cada uma, gravadas em áudio e transcritas.

Segundo Balogun, Huff e Johnson (2003), a estratégia não é de propriedade apenas dos principais executivos, mas também de todos os integrantes que a colocam em prática. Assim, torna-se relevante compreender a percepção dos diversos atores que atuam tanto em nível estratégico, quanto em nível operacional e que, em conjunto, influenciam $\circ$ ambiente organizacional da rede. A partir da entrevista em profundidade, foi possível compreender as expectativas pessoais, bem como o entendimento de cada indivíduo sobre o comportamento dos outros atores envolvidos no processo.

A coleta documental, por sua vez, é caracterizada pela coleta de materiais, escritos ou não, antes, no momento ou depois da ocorrência do fenômeno estudado. $O$ conhecimento destes documentos constituem evidências empíricas que permitem situar e suscitar as informações com maior segurança para o pesquisador (COMBES$\mathrm{SIE}, 2004)$. As fontes documentais incluíram os manuais de negociação, sites, anúncios, cartazes, panfletos e encartes promocionais da rede que apresentavam os produtos negociados conjuntamente pelos associados com os fornecedores. Os entrevis- tados também foram solicitados a apresentar o planejamento das ações das reuniões gerais e das assembleias como evidências de que determinadas práticas e atividades citadas durante as entrevistas pudessem ser ou não comprovadas.

A fim de manter coerência com a abordagem da EPS, três principais orientações foram consideradas no processo de coleta dos dados: minimizar a influência de uma teoria predefinida e modelos pressupostos; analisar o objeto utilizando diferentes meios de investigação; e quando necessário, ajustar o método de acesso às práticas propriamente ditas (FOOK, 2002). Enquanto o material foi sendo coletado, as informações relativas eram confrontadas com as informações procedentes das entrevistas, para que fosse possível obter novos insights de investigação.

A útima etapa envolveu o tratamento dos dados através da técnica de análise de conteúdo, cujo objetivo é interpretar as informações coletadas, conduzindo à organização e descrição sistemáticas das evidências que permitem atingir uma compreensão mais profunda sobre os aspectos e fenômenos da vida social de outro modo inacessíveis (OLABUENAGA; ISPIZÚA, 1989; MORAES, 1999). Inicialmente, os dados foram reunidos, revisados e organizados em pastas para que pudessem ser identificados. A releitura do conteúdo em conjunto com as anotações (palavras-chave e ideias sucintas) permitiu maior exploração e interpretação das evidências que foram sendo classificadas por grau de parentesco de sentido (BARDIN, 1994) na medida em que as diferentes práticas estratégicas eram identificadas. O Quadro 2 apresenta uma síntese das etapas que envolveram o desenvolvimento da presente pesquisa. 
As práticas estratégicas consideradas neste estudo foram aquelas que repercutiram no direcionamento, nos resultados, no posicionamento, bem como na sobrevivência da rede no mercado (JARZABKOWSKI; BALOGUN; SEIDL, 2007). Devido à dificuldade de atribuir uma perspectiva estratégica para as diferentes atividades envolvidas no processo de negociação, a identificação das práticas consideradas estratégicas ocorreu a partir da percepção dos próprios respondentes, o que serviu de referência para a análise e classificação do material à luz da teoria empregada. $\bigcirc$ próximo capítulo apresenta os resultados com destaque às três práticas estratégicas constatadas.

\section{PRATICANTES, PRÁXIS E PRÁTICAS ESTRATÉGICAS DE NEGOCIAÇÃO EM REDES DE COOPERAÇÃO}

A partir da organização e análise das evidências coletadas através das entrevistas em profundidade e da coleta documental, foi possível identificar e classificar as práticas estratégicas de negociação com fornecedores empregadas pelas redes de cooperação. De acordo com Jarzabkowski,
Balogun e Seidl (2007), na análise os três componentes da EPS foram considerados: as práticas, as práxis e os praticantes. Como resultado, três principais práticas foram identificadas: equipe de negociação; manual de negociação; e tecnologia extranet. Embora as práticas identificadas mantenham relação entre si, elas serão descritas separadamente com a integração de trechos de depoimentos dos respondentes que foram destacados durante a análise de conteúdo.

\section{Equipe de negociação}

$\mathrm{Na}$ estratégia de negociação das redes com fornecedores, uma das primeiras práticas organizacionais que emerge refere-se à formação de uma equipe de negociação. Usualmente, a equipe é formada quando o tamanho e a complexidade da rede tornamse onerosos e impeditivos à participação de todos os seus integrantes no processo de negociação, reduzindo os problemas de comunicação e atribuindo maior agilidade nos processos operacionais. A equipe é constituída por um grupo formado pelos próprios associados da rede no intuito de reunir competências complementares entre seus membros para a realização de atividades conjuntas demandadas pelo pro-

QUADRO 2 - Síntese dos procedimentos metodológicos.

\begin{tabular}{|l|l|}
\hline \multirow{2}{*}{ Etapas } & Descrição dos Procedimentos \\
\hline \multirow{2}{*}{ Etapa 1} & Survey com 50 redes de cooperação do Programa Redes de Cooperação com base em Bortolaso (2009). \\
\cline { 2 - 3 } & $\begin{array}{l}\text { Seleção das redes de cooperação com pontuação média superior ou igual a 4,00 (nível de adequação e } \\
\text { referência) em seus processos de negociação. }\end{array}$ \\
\hline \multirow{2}{*}{ Etapa 2} & $\begin{array}{l}\text { Entrevistas em profundidade aplicadas por dois técnicos especialistas em redes de cooperação com três } \\
\text { representantes de cada uma das redes selecionadas para a etapa } 2 .\end{array}$ \\
\cline { 2 - 3 } & $\begin{array}{l}\text { Coleta documental como fonte de comprovação das atividades citadas nas entrevistas - manuais de negociação, } \\
\text { sites, anúncios, cartazes e planejamentos. }\end{array}$ \\
\hline \multirow{2}{*}{ Etapa 3} & $\begin{array}{l}\text { Análise de conteúdo - revisão e organização dos materiais; interpretação dos dados e identificação das práticas, } \\
\text { práxis e praticantes. }\end{array}$ \\
\hline
\end{tabular}

Fonte: produzido pelo autores 
cesso de negociação. Em alguns casos, os membros da equipe são eleitos de modo democrático através do voto, enquanto que em outros, os membros assumem a partir de um consenso estabelecido pelos integrantes da rede. Ainda, um representante da equipe também é eleito para liderá-la a equipe:

A definição da equipe ocorre por livre e espontânea vontade dos associados.A gente busca avaliar dois principais aspectos: a disponibilidade de tempo deste associado e se as competências dele, vamos assim dizer, estão de acordo com as exigências que a equipe precisa [...]. Se ele se relaciona bem com fornecedores, por exemplo, então ele vai participar da equipe de negociação. (Presidente da rede 02, comunicação pessoal, 27 de setembro de 2013).

A formação de equipes permite a divisão interna do trabalho demandada pelas diferentes atividades que envolvem a negociação, o que garante um sistema de monitoramento mais eficiente das ações empreendidas pela rede, além da sustentação de mecanismos sociais. Através das equipes, a realização de tarefas conjuntas alcança uma nova perspectiva, visto que os problemas são mais facilmente superados ou minimizados. $A$ equipe estabelece rotinas de encontros e reuniões como um meio de organizar e discutir as atividades pendentes ou já realizadas pelos seus membros. Assim, a formação da equipe é realizada no intuito de fomentar a cooperação e a troca de informações entre os associados:

A equipe faz reuniões periódicas, normalmente semanais. Nas reuniões a gente conversa sobre os fornecedores, se o fonecedor é bom ou ruim. Tem um produto bom em oferta, a gente compartilha.Vamos trazer um novo fonecedor para a rede, ou então falamos daquele que já é nosso parceiro. (Membro da equipe de negociação da rede 08 , comunicação pessoal, 10 de junho de 20/3).

Os encontros periódicos promovem a interação e união entre os membros da equipe que compartilham valores e objetivos comuns. A equipe possui autoridade necessária, delegada pela rede, para gerenciar o processo de compra conjunta, cujo principal objetivo é comprar em escala para aumentar o poder de negociação frente aos fornecedores e reduzir o preço final dos produtos. Os objetivos são construídos a partir da identificação dos interesses comuns dos associados e caracterizam uma etapa fundamental para a rede, pois representam a base para garantir os resultados esperados:

O nosso principal objetivo [da equipe de negociação] é comprar os produtos que são de interesse de todos os associados por um preço mais baixo e ampliar cada vez mais a quantidade de fornecedores parceiros da rede. (Presidente da rede 09, comunicação pessoal, 30 de julho de 20I3).

$\mathrm{Na}$ negociação nós temos como objetivo cumprir um volume de compras dos produtos que são propostos pela equipe e aprovado em assembleia. (Presidente da rede 03 , comunicação pessoal, 20 de maio de 20I3).

O acompanhamento da equipe de negociação é realizado por meio de uma diretoria também composta por membros das empresas associadas à rede.A principal função da diretoria é gerenciar as ações empreendidas em conjunto, organizando e facilitando a realização dos objetivos gerais da rede. A diretoria oferece suporte para a concretização das decisões tomadas coletivamente, monitorando as atividades 
executadas pelos atores que constituem a equipe, solucionando problemas e impondo sanções quando necessário. Algumas redes sustentam um executivo responsável por coletar e organizar as informações dos fornecedores auxiliando a equipe na operacionalização do processo de negociação.

As tarefas demandadas pela negociação são divididas entre os integrantes que compõem a equipe e, posteriormente, discutidas conjuntamente pelos seus membros nas reuniões. Alguns associados, por exemplo, são responsáveis por buscar fornecedores de produtos ainda não negociados pela rede, enquanto que outros atuam no sentido de monitorar as parcerias já firmadas. Apesar de a equipe de negociação apresentar autonomia para as decisões operacionais referentes à negociação, as decisões estratégicas, tais como a definição dos fornecedores, itens a serem negociados e preço de compra dos produtos, são estabelecidas democraticamente em assembleias por meio do voto dos associados. A equipe de negociação estabelece um filtro das principais decisões estratégicas a serem levadas para a assembleia:

Nós temos a equipe de negociação (...) são de sete a oito pessoas que integram porque é, talvez, o grupo mais importante da rede (...) são os caras que sentam na mesa com os fornecedores, avaliam as propostas e depois levam para a diretoria e para assembleia que vai dar o aval para a negociação. (Presidente da rede 07, comunicação pessoal, 08 de maio de 20l3).

Em síntese, a equipe promove a participação e integração entre os praticantes da estratégia de negociação, a qual tem como suas principais funções: esclarecer as expertises necessárias ao trabalho em equipe, definir com os demais membros o método de trabalho, estipular coletivamente o cronograma, as atividades, ações e recursos necessários, bem como organizar reuniões periódicas de discussão e assembleias incentivando a participação de todos os integrantes da rede.

\section{Manual de negociação}

Ao planejar as compras, a rede se defronta com questões como: quais os produtos que podem ser negociados? Quais os melhores fornecedores para atender a demanda da rede? Quais os parceiros mais confiáveis ou com maior credibilidade no mercado? Quais oferecem melhores preços e condições de pagamento? Essas situações inserem a rede em um contexto de relativa incerteza quanto ao caminho para se obter a melhor negociação. Para tanto, os membros das redes desenvolvem manuais de negociação que possibilitem a escolha de caminhos adequados. Tais manuais compreendem os contatos dos fornecedores com os quais já ocorreram relacionamentos, bem como a busca por novos fornecedores.

A prática de selecionar fornecedores através de um manual preestabelecido é realizada antes da negociação propriamente dita.Tal prática ocorre no início do processo de negociação, visando a torná-lo mais eficiente, uma vez que permite reunir informações mais consistentes sobre os fornecedores mais preparados para atender as demandas da rede. $O$ manual de negociação é criado pela equipe responsável pela negociação da rede com a participação da diretoria, dos fornecedores e aprovado em assembleia. Através dele, a rede apresenta uma noção clara dos passos a serem seguidos, das providências que devem ser tomadas e dos responsáveis pelas atividades envolvidas: 
A equipe segue o manual de negociação que fornece os passos claros de como eles devem operar [...] estabelecem as condições de negociação, apresentam para a rede, falam com os fornecedores e assim por diante. (Membro da equipe de negociação da rede 04, comunicação pessoal, $24 \mathrm{de}$ maio de 20l3).

Incialmente, a equipe de negociação relaciona os produtos e serviços que devem ser negociados e definem as condições mínimas para uma transação vantajosa. As condições estão relacionadas à credibilidade dos fornecedores, qualidade dos produtos, preços, condições de pagamento e benefícios adicionais, como, por exemplo, o retorno de um valor para a rede visando ao investimento em propaganda. Tais questões são apresentadas para a diretoria e acordadas em assembleia, estabelecendo um parâmetro mínimo para que a equipe possa ter flexibilidade na negociação:

A gente reúne a rede em assembleia e discute os produtos que são de interesse da maioria dos associados e que podem ser negociados em conjunto. Com essas informações, a equipe de negociação e a diretoria estabelecem as condições mínimas de preço e condições de pagamento que tem que ser aprovadas em assembleia. Com isso, a equipe tem um parâmetro para receber os fornecedores e negociar com eles. (Membro da equipe de negociação da rede 04 , comunicação pessoal, 24 de maio de 20I3).

Após a definição dos parâmetros, os fornecedores são convidados a participar individualmente de uma reunião para a negociação. Os fornecedores apresentam um conjunto de ofertas e recebem contrapropostas até chegarem em um acordo satisfatório para ambos. As propostas dos fornecedores são posteriormente analisadas e aquelas que melhor atendem os interesses da rede são selecionadas pela equipe de negociação para a aprovação final em assembleia:

Os nossos fornecedores, todos têm que passar pela assembleia.Vamos fazer parceria com a Tigre, então a equipe de negociação estabelece toda a relação de preço, prazo de entrega, condições, tudo, e leva para assembleia. Nós temos a tabela com desconto de $2 \%$ e com prazo de tanto pra pagar. Como este novo fornecedor não era fornecedor até então, a partir de agora vai para assembleia. A decisão de quais fornecedores vão fornecer para a rede são feitas sempre em assembleia. (Presidente da rede 07, comunicação pessoal, 08 de maio de 20/3).

Pode haver vários motivos para a rede selecionar um fornecedor para a negociação. $O$ roteiro é capaz de sistematizar estes motivos de modo mais criterioso e consciente, resultando em acordos mais vantajosos e permitindo à rede alcançar fornecedores que qualifiquem a percepção dos clientes em relação aos produtos e serviços oferecidos. Essa qualidade está constantemente vinculada à imagem pela qual a rede é percebida no mercado, através de fornecedores que proporcionem a satisfação do cliente final e minimizem os problemas de qualidade.

Ainda, o manual consiste em uma prática que contribui para $\circ$ aprendizado da rede. Caso a rede não possua um modelo devidamente documentado, cada substituição de membro da equipe pode resultar em perdas relacionadas à aprendizagem coletiva, dado que o associado 'carrega' consigo o conhecimento tácito que não é transformado em conhecimento explícito para a rede. 


\section{Tecnologia extranet}

Embora a negociação normalmente seja firmada de maneira presencial junto ao representante do fornecedor que visita a equipe de negociação da rede, a prática de execução da compra conjunta ocorre por meio do emprego de tecnologias capazes de centralizar os procedimentos e informações de compra dos associados em um único sistema ou portal denominado de extranet. A extranet consiste em uma rede de computadores privada utilizada pelos associados e fornecedores com o intuito de gerenciar a compra conjunta.A ideia central de uma extranet é melhorar a comunicação da rede com seus fornecedores parceiros, no intuito de acumular uma base de conhecimento que possa auxiliar o relacionamento comercial e criar novas soluções organizacionais.

Nas redes de cooperação pesquisadas, a extranet constitui um sistema pelo qual os associados acessam as informações sobre os produtos e preços, assim como realizam os pedidos para os fornecedores. $\mathrm{O}$ emprego do sistema ocorreu, principalmente, devido à expansão geográfica e ao crescimento do número de integrantes das redes, permitindo maior facilidade de acesso, agilidade na atualização e controle no uso das informações fornecidas entre os associados e os fornecedores parceiros.

O acesso ao sistema ocorre através do site das redes, no qual os associados e fornecedores devidamente registrados navegam previamente autenticados por um login e senha. O montante dos pedidos é reunido pelo sistema, que envia aos fornecedores o volume total demandado pelos integrantes da rede.Ainda, em alguns casos, os recursos incluem o pagamento de fatura, comunicação direta com os forneceores e controle de acesso ao sistema:
Nós temos um sistema de compras [extranet] onde os associados enviam suas necessidades, suas faltas [demandas de produtos]. O sistema monta o volume total e envia para os fornecedores. Estas compras são geralmente duas vezes mensais. Algumas são feitas uma vez mensal. Produtos de mais baixo giro é uma vez mensal. (Associado da rede 09, comunicação pessoal, 30 de julho de 20/3).

Depois que a negociação é feita, o sistema reúne todos os pedidos dos associado. Os nossos fornecedores têm uma chavezinha [login e senha] que eles entram lá e recolhem todas as demandas na sexta-feira. (Associado da rede 08, comunicação pessoal, 10 de junho de 2013).

$\mathrm{Na}$ prática de adoção da extranet para a compra conjunta, um membro da equipe de negociação ou executivo da rede torna-se responsável por gerenciar o sistema, o que envolve a organização e realização dos pedidos a partir do volume total, bem como o monitoramento do valor individual demandado por cada membro integrante da rede. $O$ monitoramento é visto como a garantia de que cada associado está cumprindo a sua meta mínima de compras para que a rede alcance os benefícios em termos de prazos, descontos, bonificação para investimento em propaganda e outras condições anteriormente acordadas com os fornecedores:

Nós temos o portal do associado no site da rede [extranet]. É um sistema relativo às informações de compra dos associados que são lançados lá. Essas informações são puxadas com a administração da rede para bater com as negociações que foram feitas com os fornecedores (...) A gente consegue saber quanto cada associado comprou e quanto que falta para cumprirmos o vo- 
lume que foi acertado com os fornecedores. (Membro da equipe de negociação da rede 03 , comunicação pessoal, 23 de maio de 20/3).

O acesso ao extranet pelos associados é periódico conforme as datas do calendário de pedidos. Normalmente, o acesso ocorre no próprio estabelecimento dos membros associados. Ainda, além dos associados, os funcionários das empresas integrantes das redes também são responsáveis por coletar as informações referentes às características dos produtos, preços, condições de pagamento, e realizar os pedidos.

Assim, é possível observar que a extranet conecta os associados com os fornecedores, facilitando e agilizando a logísitca de pedidos em uma plataforma centralizada. Sua implementação aumenta significativamente o nível de controle das informações dos associados da rede, permitindo uma gestão mais eficaz da compra conjunta ao garantir o cumprimento dos requisitos acordados na negociação, tais como o volume mínimo de compras, preços, condições de pagamento e benefícios adicionais. Em algumas redes, um relatório do histórico de compras individual é enviado para cada associado e o associado que mais comprou dos fornecedores parceiros é premiado pela rede.

É importante ressaltar que nem todas as empresas das redes pesquisadas possuem bons conhecimentos e competências informáticas. Mesmo assim, todas as redes resolveram implementar a extranet, que é vista como uma plataforma indispensável para o processamento de informações relativas à negociação e para a comunicação entre os membros e com os fornecedores. Para tanto, algumas redes disponibilizaram a seus membros cursos de capacitação or- ganizados em parceria com as empresas desenvolvedoras dos softwares.

\section{Discussão e Conclusões}

Nesta pesquisa, adotamos a perspectiva teórico-metodológica da EPS para a identificação e análise das práticas estratégicas de negociação de 14 redes de empresas varejistas formadas pelo Programa Redes de Cooperação do Governo do Estado do Rio Grande do Sul com seus fornecedores. Uma vez que as redes de cooperação apresentam diferenças significativas das demais formas de organização (VERSCHOORE; BALESTRIN, 2008), torna-se relevante compreender as práticas estratégicas que permitem o desenvolvimento deste modelo de negócio. Assim, identificamos e analisamos três práticas estratégicas frequentes na negociação das redes de cooperação com fornecedores.

Equipes de negociação. $\mathrm{O}$ crescimento do número de associados de uma rede de cooperação empresarial permite a divisão e especialização do trabalho entre seus membros. Através de processos democráticos, alguns integrantes são escolhidos para formar equipes com finalidades específicas. Especialmente no segmento varejista, a formação de equipes de negociação é frequente pela oportunidade de se relacionar e contratar os fornecedores, além de gerenciar as compras. Nas práxis das redes analisadas, além da busca por novos fornecedores e do monitoramento daqueles já parceiros da rede, as equipes procuram compartilhar suas ações e resultados com os demais membros. Como foi destacado na análise, as equipes procuram a integração e a participação de todos os membros.Assim, pode-se inferir que a prática estratégica de formação de equipes de 
negociação, além de seu objetivo mais direto (a negociação), contribui para reforçar a organização e a estrutura estratégica das redes de cooperação empresarial.A formação de equipes de negociação representa uma evolução organizacional que não somente mantém, mas também reforça a horizontalidade das redes.

Manuais de negociação. $O$ processo de negociação claramente comporta a coleta de informações sobre os fornecedores e - desenvolvimento de conhecimentos e competências específicas entre seus membros. Pela já citada procura de compartilhar ações e resultados, as equipes de negociação devem formalizar a sabedoria amadurecida. Nas práxis das redes analisadas, encontramos diversas ações que vão nesta direção, como o preenchimento de listas de contatos, o envio de relatórios via e-mail e até o desenvolvimento de manuais de negociação. Tais manuais permitem a organização do aprendizado e sua transmissão. Dessa forma, a capacidade de negociação das redes é mantida e progressivamente evoluída, apesar da mudança da composição das equipes, que é natural ao processo democrático. Como no caso anterior, também esta prática estratégica reforça a organização em rede. Uma das características das redes é habilitar e promover o fluxo de informações e de conhecimento. Por meio de práticas estratégicas como esta, as redes de cooperação empresarial se tornam redes de aprendizagem.

Tecnologia extranet. Há um loop de feedback positivo entre a difusão e a incidência da organização em rede e o emprego de tecnologias da informação e da comunicação. Também nas redes analisadas se manifesta esta correlação. $O$ crescimento do número de membros das redes e a expan- são do porte de sua ação tornam necessária a adoção de formas mais eficientes de compartilhar as informações e de comunicar. Nesta direção, os membros das redes passaram a se conectar entre eles e com os fornecedores através de redes privadas de computadores. Também nesta terceira prática estratégica, a adoção de tecnologias extranet reforça a organização em rede.

Devido à diversidade de atores e seus respectivos interesses envolvidos, reconhecemos a complexidade da estratégia nas redes de cooperação empresarial analisadas. Percebemos, também, os limites dos modelos das redes que permitiram à alta gestão predefinir planos estratégicos a serem executados pelos seus demais membros em um dualismo pensar/agir. Não negamos a importância de tais modelos para a compreensão da estratégia e para sua elaboração. No entanto, afirmamos a necessidade da prática estratégica. Entendida como o conjunto articulado de práticas sociais cotidianas, a estratégia é construída e continuamente reconstruída nas ações e interações diárias de seus praticantes (WHITTINGTON, I996; JARZABKOWSKI; SPEE, 2009).

A adoção da abordagem da estratégia como prática social possibilitou identificar as práticas estratégicas no contexto da negociação das redes com seus fornecedores. Jarzabkowski, Balogun e Seidl (2007) ressaltam que as práticas são compreendidas como estratégicas quando produzem impacto nos resultados das organizações, possibilitando vantagens competitivas. Por meio da análise, é possível perceber que as três práticas estratégicas permitem a qualificação do sistema de negociação da rede, gerando maior poder de barganha e ganhos em escala para as empresas associadas. 
Também foi possível identificar os praticantes da estratégia de negociação, isto é, os atores responsáveis pelo desenvolvimento das atividades relacionadas às práticas estratégicas (JARZABKOWSKI, 2003; WHITTINGTON, 2006). Mesmo que a diretoria e a equipe de negociação atuem como praticantes mais presentes nas práticas de negociação, a estrutura em rede reforça a participação dos demais associados através de decisões coletivas, compartilhamento de informações e compra conjunta. Assim, apesar de algumas atividades serem desenvolvidas por alguns membros específicos, os resultados gerados por elas só podem ser alcançados mediante a atuação coletiva de todos os integrantes (WHITTINGTON, 2006).

Ainda, segundo Whittington (2002), é possivel perceber que existem práxis previsíveis, atividades e comportamentos rotineiros dos praticantes que se repetem no desenvolvimento da cultura organizacional. As reuniões com fornecedores, gerência de compras, compartilhamento das ações e resultados com os demais membros da rede, criação de lista de contatos, relatórios e organização dos pedidos representam alguns exemplos. Porém, também existem imprevistos e acasos, enganos e intuições que concorrem à contínua evolução da estratégia (WHITTINGTON, 2006). Assim, a estratégia é planejada, mas também rediscutida, renegociada e reelaborada pelos seus praticantes em um processo contínuo de evolução. Desdobra-se do planejamento, mas também se ergue na prática.

O contínuo processo de evolução das práticas estratégicas das redes de empresas pode ser compreendido a partir de fatores internos e externos às redes, conforme destacado por Goffman (1983). O crescimento do número de membros das redes, por exemplo, faz com que se torne onerosa e impeditiva a participação igualitária de todos os associados no processo de negociação. Assim, algumas práticas são reconstituídas no intuito de gerar agilidade nos processos e reduzir os problemas de comunicação entre os integrantes. Fatores externos também contribuem para o desenvolvimento das práticas. As novas tecnologias, por exemplo, além de facilitar e acelerar a operacionalização de determinadas atividades incumbidas à rede, tais como a compra de produtos e serviços dos fornecedores, permitem às redes estabelecer uma comunicação mais intensa promovendo a troca de conhecimento e a geração aprendizagem.

As redes são constituídas a partir do conjunto de práticas pelas quais seus integrantes encontram-se engajados fortalecendo o sistema de relações sociais. $\mathrm{Na}$ negociação com fornecedores, as evidências obtidas pela pesquisa reforçam a perspectiva de Jarzabkowski (2005), pois revelam que as práticas estratégicas são constituídas e recostituídas a partir dos praticantes que, organizados em rede, trocam conhecimentos e ampliam a capacidade de aprendizagem, estabelecendo um ambiente de contínua evolução que aumenta o potencial de ganho das empresas associadas. Esse contexto favorece o desenvolvimento da rede, pois amplia a base de conhecimento, bem como propicia $o$ alcance de fornecedores com credibilidade no mercado, o que impacta a percepção dos clientes no que se refere aos produtos e serviços ofertados.

Ainda, o postulado teórico de que as redes de cooperação estruturam suas estratégias por meio de um modelo coletivo e colaborativo (BALESTRIN; VERSCHOO- 
RE, 2008) é confirmado pelas três práticas estratégicas identificadas e analisadas: todas reforçam a organização em rede. Este modelo de organização favorece um tipo de processualidade horizontal e interativo, de fluxo contínuo entre conexões variáveis, ou seja, um tipo de processualidade que admite imprevistos e até desvios. Por esta razão, a EPS constitui uma perspectiva teórico-metodológica especialmente adequada para conduzir pesquisas em redes de cooperação empresarial e em outras realidades organizacionais que se fundam sobre a organização em rede.

Por fim, o presente trabalho oferece di- retrizes para que as redes possam qualificar o sistema de negociação com fornecedores por meio da adoção das práticas estratégicas analisadas. A principal limitação da pesquisa refere-se ao fato de que todas as redes analisadas estão concentradas no estado do Rio Grande do Sul, podendo apresentar particularidades quanto às características culturais da região. No entanto, este estudo possibilita que novas pesquisas similares sejam realizadas no intuito de identificar e analisar novas práticas estratégicas ligadas à negociação ou a outras dimensões da construção e contínua reconstrução da estratégia nas redes de cooperação. 


\section{REFERÊNCIAS}

AMATO NETO, J. Redes entre organizações: domínio do conhecimento e da eficácia operacional. São Paulo: Atlas, 2005.

ASTLEY, W. G. Toward an appreciation of collective strategy. Academy of management review, v. 9, n. 3, p. 526-535, 1984.

BALESTRIN,A;VERSCHOORE,J. Redes de cooperação empresarial: estratégias de gestão na nova economia. Porto Alegre: Bookman Editora, 2008.

BALOGUN, J; HUFF,A. S; JOHNSON, P.Three responses to the methodological challenges of studying strategizing. Journal of Management Studies, v. 40, n. I, p. 197 224, 2003.

BARDIN, L. Análise de Conteúdo. Lisboa: Edições Setenta, 1994.

BORTOLASO, I; PERUCIA, A. Processo de Negociação: Praticas de Gestão de Redes de Cooperação. In: ANTUNES, J; BALESTRIN A; VERSCHOORE, J. (Ed.), Práticas de Gestão de Redes de Cooperação (pp.83-89). São Leopoldo: Editora Unisinos, 2010.

BORTOLASO, I. Proposta de construção de um modelo de referência para a avaliação de redes de cooperação empresariais (Mestrado em Engenharia de Produção e Sistemas) - Universidade do Vale do Rio dos Sinos. São Leopoldo: UNISINOS, 2009.

CAMPBELL, A; GOOLD, M. The collaborative enterprise. Why links across the corporation often failand how to make them work. Reading, MA: Perseus Books, 1999.

COMBESSIE, J. C. O método em sociologia: o que é, como se faz. São Paulo: Editora Loyola, 2004.
DE MOOR, A; WEIGAND, H. Business negotiation support: theory and practice. International Negotiation, v. 9, n. I, p. 3I-57, 2004.

FIELDS, C. R. I. O; DIMAGGIO, P. J; POWELL,W.W.The iron cage revisited: Institutional isomorphism and collective rationality in organizational fields. American Sociological Review, v. 48, n. 2, p. |47-160, 1983.

EBERS, M; JARILLO, J. C. Preface: The Construction, Forms, and Consequences of Industry Networks. International Studies of Management \& Organization, v. 27, n. 4, p. 3-21, 1997.

FOOK, J. Theorizing from practice towards an inclusive approach for social work research. Qualitative Social Work, v. I, n. I, p. 7995, 2002.

FISHER, R; URY, W; PATTON, B. Como chegar ao sim: negociação de acordos sem concessões. Rio de Janeiro: Imago, 2005.

GOFFMAN, E. A representação do eu na vida cotidiana. Petrópolis:Vozes, 1983.

GRANDORI, A; SODA, G. Inter-firm networks: antecedents, mechanisms and forms. Organization studies, v. 16, n. 2, p. 183-214, 1995.

HAMES, D. S. Negotiation: closing details, setting disputes and making team decisions. Thousand Oaks: Sage, 2012.

HUMAN, S. E; PROVAN, K. G. An emergent theory of structure and outcomes in small-firm strategic manufacturing networks. Academy of Management Journal, v. 40, n. 2, p. 368-403, 1997.

JARILLO, J. C. Strategic Networks: Creating the Borderless Organization. Oxford: Butterwoth
-Heinemann, 1993.

JARZABKOWSKI, P. Strategic practices:An activity theory perspective on continuity and change. Journal of Management studies, $v$. 40, n. I, p. 23-55, 2003.

JARZABKOWSKI, P. Strategy as practice: an activity-based approach. London: Sage, 2005.

JARZABKOWSKI, P; PAUL SPEE, A. Strategy-as-practice:A review and future directions for the field. International Journal of Management Reviews, v. II, n. I, p. 69-95, 2009.

JARZABKOWSKI, P; BALOGUN, J; SEIDL, D. Strategizing: The challenges of a practice perspective. Human relations, v. $60, n$. I, p. 5-27, 2007.

JOHNSON, G; MELIN, L;WHITTINGTON, R. Micro strategy and strategizing: towards an activitybased view. Journal of management studies, v. 40, n. I, p. 3-22, 2003.

JOHNSON, G. Strategy as practice: research directions and resources. Cambridge: Cambridge University Press, 2007.

MACIEL, C. O; AUGUSTO, P. O. M. A practice turn e o movimento social da estratégia como prática: está completa essa virada?. Revista de Administração Mackenzie, v. I4, n. 2, p. I55, 20 I3.

MILES, R. E; SNOW, C. C. Organizations: New concepts for new forms. California management review, v. 28, n. 3, p. 62-73, 1986.

MANTERE, S. Strategic practices as enablers and disablers of championing activity. Strategic organization, v. 3, n. 2, p. I57-184, 2005.

MINTZBERG, H; AHLSTRAND, B; LAMPEL, J. Safári da estratégia. Bookman Editora, 2009. 
MORAES, R. Análise de conteúdo. Revista Educação, Porto Alegre, v. 22, n. 37, p. 7-32, 1999.

NOHRIA, N. Is a network perspective a useful way of studying organizations. Hickman, Gill Robinson. Leading organizations: perspectives for a new era. California: Sage Publications, p. 287-30I, 1998.

OLABUÉNAGA, J. I. R; URIBARRI, M. A. I. La descodificación de la vida cotidiana: métodos de investigación cualitativa. Universidad de Deusto; Deustuko Unibertsitatea, 1989.

OLIVER, A. L; EBERS, M. Networking network studies: an analysis of conceptual configurations in the study of inter-organizational relationships. Organization studies, v. 19, n. 4, p. 549-583, 1998.

PERROW, C. B. Small Firm Networks. Institutional change: Theory and empirical findings, p. II I, I 993.

SAUERBRONN, F. F; FARIA, A. A. Agência em estratégia: conectando prática social e codeterminação. Revista de Administração Mackenzie, v. I2, n. 6, p. 49, 20 I I. SCHATZKI, T. R. Social practices: A Wittgensteinian approach to human activity and the social. Cambridge: Cambridge University Press, 1996.

SDECT. Secretaria do Desenvolvimento Econômico, Ciência e Tecnologia do Estado do Rio Grande do Sul (20I5). Endereço eletrônico, arquivado em http://www. sdect.rs.gov.br/redes-de-cooperacao

TRIVINOS, A. N. S. Introdução à pesquisa em ciências sociais: a pesquisa qualitativa em educação. São Paulo:Atlas, 1990. TURETA, C; DE LIMA, J. B. Estratégia como prática social: o estrategizar em uma rede interorganizacional. Revista de Administração Mackenzie, v. I2, n. 6, p. 76, 201 I. VERSCHOORE, J. (2006). Redes de Cooperação Interorganizacionais: A Identificação de Atributos e Benefícios para um Modelo de Gestão (Doutorado em Administração) - Porto Alegre, UFRGS, 2006

VERSCHOORE, J; BALESTRIN, A. Fatores relevantes para o estabelecimento de redes de cooperação entre empresas do Rio Grande do Sul. Revista de Administração de Empresas, v. 12, n. 4, p. 1043-1069, 2008.

VERSCHOORE, J; BALESTRIN, A. A associação em redes de cooperação influencia os resultados de pequenas e médias empresas? Ciências Sociais Unisinos, v. 46, n. I, p. 105-I 15, 2010.

VON ENDE, M. Redefort: uma Avaliação dos Benefícios EconômicoFinanceiros Percebidos por Integrantes de PME em uma Rede de Cooperação. In: VERSCHOORE, J. Redes de Cooperação: uma nova organização de pequenas e médias empresas no Rio Grande do Sul (pp. 245259). Porto Alegre: FEE, 2004.

VAN WAARDEN, F. Emergence and development of business interest associations. An example from the Netherlands. Organization Studies, v. 13, n. 4, p. 52|-56|, 1992.

WEGNER, D; PADULA, A. D. Quando a cooperação falha: um estudo de caso sobre o fracasso de uma rede interorganizacional. Revista de Administração Mackenzie, v. I3, n. I, p. I45, 2012.

WHITTINGTON, R. Strategy as practice. Long range planning, v. 29, n. 5, p. 73I-735, 1996.

WHITTINGTON, R. Practice perspectives on strategy: unifying and developing a field. In: Academy of Management Proceedings. Academy of Management, 2002. p. CI-C6.

WHITTINGTON, R. Estratégia após - modernismo: recuperando a prática. Revista de administração de empresas, v. 44, n. 4, p. 44-53, 2004.

WHITTINGTON, R. Completing the practice turn in strategy research. Organization studies, v. 27, n. 5, p. 613-634, 2006.

WILSON, D. C.; JARZABKOWSKI, P. Thinking and acting strategically: New challenges for interrogating strategy. European Management Review, v. I, n. I, p. I4-20, 2004. 